\title{
Development of the capacity for health regulation in Mexico
}

\author{
Carlos Santos-Burgoa, ${ }^{1}$ Manuel Urbina-Fuentes, ${ }^{2}$ Juan Ángel Rivera-Dommarco, ${ }^{3}$ Martha Hijar, ${ }^{4}$ \\ Julio Salvador Sánchez-Tépoz,, Juan Carlos Gallaga-Solórzano, ${ }^{5}$ Rocío del Carmen Alatorre Eden-Wynter, ${ }^{5}$ \\ Armida Zúniga-Estrada, ${ }^{5}$ Ricardo García-Sarubbi, ${ }^{6}$ Claudia Gabriela García-Chávez ${ }^{7}$ and \\ Ana Carolina Ariza ${ }^{8}$ \\ ${ }^{1}$ The George Washington University, Milken Institute School of Public Health, Washington DC, USA; ${ }^{2}$ Academia Nacional de Medicina, Permanent \\ Committee for the Study of Health Social Determinants, Ciudad de México; ${ }^{3}$ Secretaría de Salud, Instituto Nacional de Salud Pública, Directorate \\ General, Ciudad de México; ${ }^{4}$ Fundación Entornos, Morelos; ${ }^{5}$ Comisión Federal para la Protección contra Riesgos Sanitarios, Ciudad de México; \\ ${ }^{6}$ Secretaría de Salud, Consejo Nacional para la Prevención de Accidentes Technical Secretariat, Ciudad de México; ${ }^{7}$ Secretaría de Salud, Instituto \\ Nacional de Salud Pública, Center of Nutrition and Health Research, Ciudad de México; ${ }^{8}$ Consejo Nacional de Ciencia y Tecnología, Ciudad de \\ México, Mexico
}

\begin{abstract}
The National Academy of Medicine is an essential space to discuss regulatory science in health, and to position its impact on health and economy. Framed within the stewardship role of the health authority, health regulation is the action of protecting the population against involuntary health hazards against which the individual cannot protect him/herself. It is an essential function of public health, an institutional component of the health system and, therefore, linked to its reforms and to universal coverage. Regulation has its support on an epidemiological, organizational, legal, sociological and economic theoretical body. It has a methodological body that supports its regulatory process based on risk analysis and that is translated into regulations, implementations, compliance, monitoring and evaluation of the regulation. It has a professional, financial, organizational, legal and governance architecture. Given its universal action, it has a widespread impact on the population and a substantial economic effect, influencing on at least $17 \%$ of regional international trade. Health through its regulatory authorities should be an early part of international trade discussions.
\end{abstract}

KEY WORDS: Regulation. Health system. Development. Globalization. Noncommunicable diseases. Governance.

Date of reception: 21-06-2017

Date of acceptance: 18-04-2018

DOI://dx.doi.org/10.24875/GMM.M18000160
Gac Med Mex. 2018;154:305-327

Contents available at PubMed www.gacetamedicademexico.com 